\title{
Invasion from the South: Social Construction of the Haitian "Other" in The Bahamas
}

\section{Charmane M. Perry University of Wisconsin ${ }^{1}$}

\begin{abstract}
Since 1957, the Bahamian government has been trying to control the migration of undocumented Haitians to and their movement through The Bahamas. Due to the continued and incessant migration and the question of citizenship for Haitians, Bahamians have come to perceive Haitians as a threat to the national and cultural sovereignty of The Bahamas. The media, government policies, and everyday constructions of Bahamian identity have played a significant role in socially constructing the image and status of Haitians residing in The Bahamas. The perception and internalization of these images and ideas have resulted in the denial of human rights for Haitians and people of Haitian descent residing in The Bahamas.
\end{abstract}

\section{INTRODUCTION}

This article will explore how the media, government policies, and identity construction have played a critical role in the ascribed racialized images and attitudes towards Haitians in The Bahamas. First, I will show that the media have played a substantial role in increasing anti-Haitian sentiment primarily through three factors: consistent emphasis on the proximity of Haiti to The Bahamas, inaccurate reports on the size of the Haitian population residing in The Bahamas, and onedimensional visual representation of Haitians. Second, I will also explore how legislation passed during the era of independence constructed an image in the imagination of Bahamians regarding who could and who could not be a Bahamian. After the election of the first successful Afro-Bahamian political party (the Progressive Liberal Party) and the change in leadership, Haitians became the racialized and inferior other (a status previously occupied by Afro-Bahamians) which is directly related to the exploitation of their labor in The Bahamas. Lastly, I will explore how Bahamians perceive and construct their identity in binary opposition to the cultural and historical representations of Haiti and Haitians which is also racist. All of these factors are interrelated and, most importantly, intrinsic to each one is the concept of coloniality, providing a racial lens in which Haitians are considered to be culturally inferior, different, and primitive which becomes a seemingly natural justification for the exploitation of their labor and for the denial of their human rights.

Before proceeding, let's define coloniality and why it is being used as a lens to understand the treatment of Haitians in The Bahamas. In "On the Coloniality of Being" Maldonado-

${ }^{1}$ Charmane M. Perry, Doctoral Student, Department of Africology, University of Wisconsin-Milwaukee, Milwaukee, Wisconsin.

E-mail: cmperry@uwm.edu

APA reference: Perry. C. M. (2014). Invasion from the South: Social construction of the Haitian 'Other' in The Bahamas. The International Journal of Bahamian Studies, 20(1), 1-12. https://doi.org/10.15362/ijbs.v20i1.197

(C) C.M. Perry, 2014. Journal compilation (CThe International Journal of Bahamian Studies, 2014 
Torres (2007) states that "coloniality ... refers to long-standing patterns of power that emerged as a result of colonialism, but that define culture, labor, intersubjective relations, and knowledge production well beyond the strict limits of colonial administration" ( $p$. 243). This means that colonialism and coloniality are antonyms. Whereas colonialism is the political and economic domination of a people by another, coloniality is the product of colonialism and thus outlasts colonialism, manifesting itself in the everyday life of people across the globe. However, coloniality is not a product of any form of colonialism but is particular to the discovery and conquest of the Americas. It is at this socio-historical moment that capitalism and domination became intertwined which resulted in world capitalism. Quijano (2000) asserts that:

Two historical processes associated in the production of that space/time converged and established the two fundamental axes of the new model of power. One was the codification of the differences between conquerors and conquered in the idea of race, a supposedly different biological structure that placed some in a natural situation of inferiority to the others. The conquistadors assumed this idea as the constitutive, founding element of the relations of domination that the conquest imposed. On this basis, the population of America, and later the world, was classified within the new model of power. The other process was the constitution of a control of labor and its resources and products. This new structure was an articulation of all historically known previous structures of control of labor, slavery, serfdom, small independent commodity production and reciprocity, together around and upon the basis of capital and the world market (p. 534).

These two axes produced new social identities that functioned around the idea of race as a biological entity. Race signified one's degree of humanity and race functioned to situate people, according to their new ascribed racial identity, in the new international division of labor. And so, we have two things being structurally linked race / labor and modernity / coloniality.

In this article, I argue that coloniality is critical to understanding the treatment of Haitians in The Bahamas because it was not until after the success of the Progressive Liberal Party (PLP) that the party's platform increasingly focused on immigration. The PLP went from anti-racist rhetoric against the United Bahamian Party (UBP) to anti-Haitian sentiments after their election to the House of Assembly. According to Saunders (2003):

Before majority rule, race relations within The Bahamas typified colonial social organization in which a white minority maintained political and economic power through racial segregation. Racial discriminatory practices barring black Bahamians from full political participation and opportunities for economic gain fuelled the campaign for majority rule. The founding of the PLP in 1953 challenged the social status quo and the leadership of the Bay Street Boys, the white oligarchy named after the prominent commercial street in Nassau that later formed the UBP. The PLP's platform showed a concern for redressing past discriminatory barriers to the social advancement of black Bahamians (p. 39).

In their fight against the United Bahamian Party, the PLP accused the party of trying to alter Bahamian identity by encouraging the immigration of whites (from Europe and the United States) and excluding people of African descent (Haitians, Jamaicans, and African-Americans) through immigration policies. However, after the success of the 
PLP, their attack on immigration increased and affected not only whites but also blacks, in particular Haitians. In addition, after 1967, the changes in social services and education catalyzed the upward mobility of many AfroBahamians. As a result:

Haitians performed an essential economic function in taking jobs that Bahamians no longer wanted.... Very many Bahamians came to depend on Haitians for performing agricultural and gardening labour... Scarcely a Bahamian of any substance but had their 'own' Haitian, on whom they were to a degree dependent, but who in turn depended on them for protection, in the form of help with the authorities or documentations, as well as for wages (Craton, 1995, pp. 274-275).

Coloniality plays a significant role in the treatment and representation of Haitians in The Bahamas. They are the racialized, inferior, and non-human other. AfroBahamians, once considered inferior by the white minority, became superior and more human in the post-independence period and in turn dominated and controlled Haitians. Let me be clear; this does not negate the role of class. Haitians have reported feeling more discrimination and prejudice from working class Afro-Bahamians than from other Bahamians (Robertson, 2001, p. 77). Working class Afro-Bahamians perceive Haitians as an economic threat because they will work for lower wages. Furthermore, the undocumented Haitians who enter The Bahamas come from an impoverished and marginalized status in Haiti. This explains their method of entry. Instead, I am arguing that because race and the division of labor are structurally related, Haitians (who have already been historically racialized and demonized as inferior) are considered nonhuman, performing the most menial jobs which, in the lens of coloniality, is a natural justification for their domination and exploitation.

Media

The media have played a significant role in the expansion and institutionalization of xenophobia, negative attitudes, hatred, and ignorance due to their representation of Haitians in The Bahamas. According to Hall (1997), “... representation is a complex business and, especially when dealing with 'difference', it engages feelings, attitudes and emotions and it mobilizes fears and anxieties in the viewer, at deeper levels than we can explain in a simple, common sense way" ( $p$. 229). Bahamians fear the presence of the Haitian community in The Bahamas and believe they are a threat to the cultural and national sovereignty of The Bahamas. Yet, these fears are rooted in ideas emanating from the state and are exacerbated by ignorance and the way that Haitians have been portrayed in the media. In addition, the perception of Haitians as a cultural and national threat is a product of racial constructions of identity rooted in colonialism. Thus, their representation and difference must also take into consideration the ways in which coloniality complicates the perception of Haitians in The Bahamas.

In newspapers, Haitians are described as a burden, a drain on society, living tax-free, a problem, a threat to Bahamian development, a national pain, a daily assault on Bahamian sovereignty, and the single greatest threat to The Bahamas (Johnson et al., 2005). The media also give the impression that Haitians are taking over the country by the use of terms such as "Haitian hordes", "Haitian invasion", and describing Bahamian society as "under assault" (pp. 10-11). Moreover, mainstream Bahamian newspapers, specifically The Nassau Guardian and The Tribune, support these descriptions and increase fear by reporting inaccurate estimates of the Haitian community citing anywhere from 50,000 to 400,000 in various articles when in fact there 
has been slight population growth in the last 15-20 years (pp. 11-13). Statistics suggests that from 1963 to 2000, the resident Haitian community has grown from 4,170 to 21,426 (Fielding, Ballance, Scriven, McDonald, \& Johnson, 2008, p. 45). If the newspapers are correct, this would suggest that the undocumented population could be as high as hundreds of thousands when in fact the total Bahamian population is slightly over 300,000 (Fielding et al., 2008). Haitian migration was, and continues to be, categorized as the "invasion from the south", "invasive" and the "Haitian stampede" (Craton, 1995). These claims are printed in the newspapers without any empirical evidence to substantiate them. Such descriptions carry racial undertones, suggesting that Haitians are foreign and that their invasive presence will result in the cultural and societal degradation of The Bahamas.

The Nassau Guardian and The Tribune also add to the fear of the inevitable loss of Bahamian cultural and national sovereignty with article headlines such as "Creole 'will be the dominant language within ten years" (Creole, 2005, p. 9) and "Bahamians of Haitian descent 'will make up swing vote in 10-15 years" (Herig, 2005, p. 1). Both articles add to the anti-Haitian phobia and the idea that The Bahamas is under attack. The latter article addresses the political impact that Haitian-Bahamians will inevitably have in The Bahamas which in many ways further reproduces an image of Haitians as invaders who will take over the country. Further, the perception of Haitian Creole as an imposed foreign language is also extremely racialized and located in coloniality. Within Haiti, Haitian Creole has historically been linked to the black peasantry, a sign of African cultural retention and thus, primitive. As a result, the elites upheld French as the national language until 1983 when both became the official languages of Haiti (Bellegarde-Smith, 2004, pp. 214-215). Even the usage of the word creole as the name of the language insinuates the undervaluing of Haitian Creole (Pierre, 2006, p. 269). Furthermore, some Bahamians also view Haitian Creole with negativity arguing that instead of learning Haitian Creole, Spanish or French should be taught (Turnquest, 2005, p. 5).

Just as critically, in the public discourse, no distinction is made between the categories of Haitians and their legal status in The Bahamas. Haitian-Bahamians, naturalized citizens, Haitian nationals with work permits, and undocumented Haitians are indiscriminately lumped into one category. In The Haitian Problem, Marshall explains the difference between being an expatriate and a migrant in the Caribbean, which is an expression of coloniality. She states that the term "migrant" developed negative connotations, became associated with inferiority, and was used as a derogatory term whereas "expatriate" described Europeans who occupied positions of higher status who originated from developed countries. In contrast to their receiving country, migrants typically come from areas with lower standards of living, have limited education and thus limited employment opportunities. Typically, migrants were black, poor, had limited formal education, and sought employment in menial and unskilled positions which the economy demanded but which Bahamians of African descent were increasingly unwilling to perform. Although Turks and Caicos Islanders and Jamaicans were also among the unskilled black workers, Haitians outnumbered them (Craton \& Saunders, 1998).

Furthermore, Marshall asserts that "when the 'migrant' has entered a country illegally, or obtained a job without official permission, his status is even lower, like the Haitian he becomes an 'illegal migrant"' (Marshall, 1979, p. 93). When journalists discuss 
Haitians as a single homogenous group, all Haitians become viewed as illegal and a problem to the country. Haitians as a people are seen as inferior and non-human because they are "illegal migrants" with little or no formal education which means they work in the most menial jobs. Furthermore, the fact that they are illegal heightens this reality because they become extremely vulnerable to exploitation.

Lastly, but extremely critical, is the eerie similarity of the stories reported by journalists. In the daily news, journalists report the same stories of Haitians attempting to enter the country, arrests, deportations, and political and public opinion (most of which are negative). According to the International Organization for Migration study on Haitian migration, the most consistent topics covered can be broken down into three groups: social issues (education, housing), political issues (law and order, citizenship) and economic issues (labor). Although the articles seem to cover a myriad of topics, the news reports lack depth on the issues associated with the migration and why Haitians are migrating as well as failing to place migration into a global and/or Caribbean context (Johnson et al., 2005).

In the summer of 2010, I conducted research in Nassau, New Providence. I had the opportunity to read newspaper clippings from the 1980s, 1990s, and 2000s in the collection at the Hilda Bowen Library at the College of The Bahamas as well as do archival research at The National Archives of The Bahamas where I viewed newspapers from the 1950s, 1960s, and 1970s. While doing my research, I began to notice that there was little qualitative difference between the content of articles concerning Haitians in The Bahamas from the 1960s and those from the latter 20th- and early 21st centuries. This observation suggests that over the last 50 years (which is essentially the length of the Haitian "problem") Bahamians have been bombarded with and have internalized negative and racialized images, words, and ideas concerning Haitians in The Bahamas.

It becomes imperative here to understand that Haitian migration to The Bahamas predates 1957 as well as the fact that migration has functioned as a way and means of life for Caribbean people (including Bahamians who emigrated to Miami and Key West in the late 19th and early 20th century). As a result of the lack of wages and opportunities in their homeland (which are the manifestations of slavery and colonialism), Caribbean migrants have travelled to other Caribbean islands, the Americas, and Great Britain since the late 19th and early 20th centuries (Richardson, 1983). As such, by 1948, there was already a small Haitian community in The Bahamas. During this period there had been little socioeconomic difference between Haiti and The Bahamas resulting in trading between merchants from the island of Tortuga (northernmost point in Haiti) and Inagua (southernmost point in The Bahamas). Tortuga, Port-de-Paix, and Cap Haïtien were particularly important trade (as well as hospital) destinations because they were more accessible to people of the southern Bahamas than Nassau. There is also evidence to suggest that the Haitian presence in the southern Bahamas in the late 19th and early 20th centuries was numerically similar to the Bahamian presence in northern Haitian port cities (Tinker, 2011). Merchants from Mathew Town Inagua who had mercantile connections in Cap Haitien and Port-de-Paix began sending their daughters to be educated in Port-au-Prince. Bahamian men who conducted business in northern Haiti also fathered children with Haitian women (Craton, 1995, p. 268). This indicates that during this period, Haitians were seen as their equal. Both groups were experiencing similar vicissitudes and helped each other because 
they needed each other.

So why is this important? First, this is critical because the original nature of Haitian migration to The Bahamas was circular, not permanent. Haitians migrated to The Bahamas to earn money and then returned to Haiti. The reality of circular migration was expressed by a common Haitian Creole proverb among the migrants: "Nou vin Nassau, nou pa vin rete se g-in-n dola nou vin chache" meaning "We come to Nassau, we don't come to stay, we come to look for dollars only" (Marshall, 1979, p. 51). Second, it is critical because when there was a mutual (as well as similar) socioeconomic relationship between The Bahamas and Haiti, the Haitian problem rhetoric did not exist. Interestingly, Craton states that "...the fortunate few non-white Bahamians who visited Haiti as tourists came back enthused by the vitality and authenticity of Haitian popular culture, and with an admiration bordering on envy for the Parisian elegance and political power of the Haitian brown elite" (Craton, 1995, p. 268). In consequence, there is a relationship between the rise of the tourist industry, the Duvalier dictatorship and the beginning of the Haitian problem. This is important because it was not until after Haiti began to regress politically and economically and The Bahamas (specifically New Providence, Grand Bahama, Eleuthera, and Abaco) flourished because of tourism that a sharp divide between Bahamians and Haitians arose and Haitians began to be treated negatively and they and their country perceived as inferior.

\section{Government Policies}

In terms of government policies, the problem of immigration has been one of the most pressing concerns for the Bahamian government since the 1960s. The increasing prosperity of the Bahamian economy due to tourism (itself a reincarnation of colonialism) resulted in an increase in opportunities and immigration. The attempt to control immigration became more critical during this period than in prior periods (Craton \& Saunders, 1998). The movement against immigration in the age of independence was a reflection of the PLP's national objective of protecting The Bahamas for Bahamians, particularly black Bahamians. Therefore, the question of immigration was critical. The Bahamas was experiencing high levels of immigration which meant the contention against immigration was not simply to open opportunities to and protect them for black Bahamians but also to prevent foreigners from accessing those same opportunities.

In an effort to control unskilled labor (i.e. black labor), the United Bahamian Party developed the Immigration Act of 1964 which prohibited the employment of foreigners without the authorization of the Bahamian government. Work was also restricted to the employment specified on the work permit (Marshall, 1979). In a further attempt to control immigration, allegedly for security reasons, and to protect job opportunities for Bahamians, the Bahamianization policy was implemented by the PLP in 1967. "Essentially, Bahamianization was attempted by the government to control the recruitment of non-Bahamian labor. Specifically targeted under this program were white foreigners recruited by the Grand Bahama Port Authority, Haitians, and Jamaicans" (Tinker, 2011 , p. 8). The Bahamianization policy was meant to provide Bahamians with the opportunity to gain better employment and business opportunities by limiting the availability and accessibility of work permits, permanent residency, and citizenship. Bahamianization also required that employers hire Bahamians over non-Bahamians. Only if a qualified Bahamian could not be found were employers allowed to hire foreign labor. Moreover, attempts to find qualified Bahamians were not to cease despite the 
position being filled (McCollin, 2002). Thus, Bahamianization must be viewed as a tactic of resisting and limiting foreign immigration.

Lastly, and most critically, after independence in July 1973, The Bahamas transitioned from jus soli to jus sanguinis in its citizenship and naturalization policies. The Independence Constitution of 1973 stated that those born in The Bahamas before July 10, 1973 were eligible for Bahamian citizenship. However, those born in The Bahamas after July 9, 1973 to non-Bahamian parents were not granted automatic citizenship. Instead, they would have to apply for citizenship within a year of their 18th birthday. Citizenship, however, was not guaranteed and applicants had to be prepared to take an oath of allegiance, make a declaration of intent on residence, renounce foreign citizenship, and, moreover, had to be cleared of anything perceived to be a threat to the interests of national security and public policy (Craton \& Saunders, 1998).

The pursuit of the policy of The Bahamas for Bahamians came at the expense of other groups. Legislation passed during the era of independence has been oppressive for the Haitian community because it has made it increasingly difficult to regularize their stay (Sears, 1994). As such, the state has been able to use its power to control and marginalize this community through legislative sanctions. Citizenship, along with work permits and permanent residency, are tactics by which the Bahamian state can control the Haitian community in The Bahamas. It is within this framework that children of Haitian descent have been legally excluded from the full rights of citizenship in the land of their birth.

Furthermore, the window of opportunity to apply for citizenship is limited to one year after one's 18th birthday. However, according to the Human Rights Delegation Report (Yale Law School, 1994), there were problems associated with this system. First, many Haitian-Bahamians were unaware of their rights to citizenship or the short window of opportunity that they had to apply for citizenship. Second, some Haitian-Bahamians knew few applicants who applied for citizenship and were interviewed within the specified time period and were granted citizenship. Lastly, and this is a very critical point, the hierarchy in citizenship has created a two-tier system of social discrimination against Haitians which intersects with ideas of Bahamian identity (this will be explained later).

Citizenship is a critical issue for HaitianBahamians. Due to citizenship laws, many Haitian-Bahamians are not citizens in The Bahamas or Haiti. In the article "Haitians Living in Limbo" (2003), a young man, Marc Sedione, discussed his frustrations and aspirations. Sedione was born in The Bahamas to Haitian parents but states that he is neither Haitian nor Bahamian. "And though he has applied three times for Bahamian citizenship and spent about $\$ 4,500$ on paperwork and lawyers, he has nothing to show for his efforts" (para. 5). Since he has no legal status, and therefore no way to elevate himself in Bahamian society, Sedione planned to make an undocumented trip to West Palm Beach to live with his family. His destination represents his desperation, his ostracism in Bahamian society, and his despair.

My point here is that through government policies, specifically work permits, citizenship, and naturalization, the Bahamian government controls the legal status of Haitians in The Bahamas. Quijano states "...a modern nation-state involves the modern institutions of citizenship and political democracy, but only in the way in which citizenship can function as legal, civil, and political equality for socially unequal people" (2003, p. 557). Furthermore, the modern 
nation-state is a power structure that dominates a group of people, in this case Haitians. If we understand the intricate relationship between the media and the state (the media functioning as a tool of the state), it is clear that both institutions play large roles in socially constructing racialized representations of Haitians by continuing to represent them (in news stories and institutionally) as illegal, a problem, and inferior.

\section{Bahamian Self and the Haitian "Other"}

The issue of a Bahamian identity provides the most visible maintenance of coloniality. While doing research in The Bahamas in 2010, I encountered a young Bahamian man who told me that Bahamians did not have an identity. He followed this statement by making a reference to Bahamians listening to reggae music and Bahamians not knowing "thyself". It was here that I first began to question what Bahamian culture is and also, what it meant to be Bahamian. If Haitians are imagined to be a threat to the cultural and national sovereignty of The Bahamas, then it becomes important to define how Bahamian identity has been constructed. According to Smith (1991), an individual's national identity is a complex mix of shared values, memories, myths, and traditions that provide the individual with a unique cultural heritage. As it pertains to The Bahamas, discourse on Bahamian national identity is a contested topic. The overall sentiment is that there is a lack of a clear and cohesive Bahamian national identity. According to Bethel (2007), it is not uncommon for Bahamian intellectuals to state that The Bahamas has little or no sense of national identity. She goes on to state that Bahamians are also skeptical of the idea of a national identity. In response to this question, some Bahamians may respond by saying "National identity?", "What is that?" or "We don't have a national identity" (p. 1).

Prior to the 1960s, the question of a national identity in The Bahamas was unheard of, and the prospect of independence developed an urgent need for Bahamians to find their true identity (Bethel, 2007). During this period, "the euphoria of independence was paralleled by a growing desire for an articulated and visible postcolonial identity-a desire stemming from a distinct lack of confidence in Bahamian cultural expression" (Rommen, 1999, p. 74). In a 1966 speech to the United Nations, Lynden Pindling stated:

"Bahamian" is not a legal term under the constitution; yet no one can say with any degree of truth that we are British. As a people we are without history, without culture, and without national identity. We study British history, British civilization, and even British weather; but about ourselves, we have no past-and under colonialism, no future. (Palmer, 1994, pp. 799-800)

Pindling's statement reinforces the idea that there was a lack of a national identity. It also suggests that it was not easy to point out things that were distinctly Bahamian and not derived from British culture. Bahamians were never British because they were colonial subjects which meant they were not human. Their racial identity was constructed during colonialism and persisted through coloniality. The lack of a clear, cohesive identity adds to the perceived cultural threat that the Haitian community is believed to be imposing on The Bahamas. According to Craton (1995), in terms of self-definition, no group of people has "served more effectively as a defining Other for the Bahamian Self than have the Haitian migrants to and through The Bahamas" (1995, p. 266). Therefore, Bahamians have constructed elements of their identity in opposition to the historical, political, social, economic, and cultural perceptions of Haiti and the Haitian community. 
Hall (1997) states that people who are perceived to be different and/or constructed as the "other" from the majority are often represented in binary opposition: "They seem to be represented through sharply opposed, polarized, binary extremes - good / bad, civilized / primitive, ugly / excessively attractive, repelling — because different / compelling — because-strange-and-exotic" (1997, p. 229). More critically is how difference (the representation of difference) is linked with questions of power. The use of the term other reflects the idea that Bahamians imagine themselves in binary extremes/forms of representation against Haitians who have also taken on racial identities. Consequently, we can recognize what it means to be Bahamian not only because of cultural and national characteristics but because it has been marked as different from Haitians.

In the era of independence, the new Bahamian state (controlled by blacks) retained elements of the colonial state (Alexander, 1994). The new black ruling party internalized and reproduced Euro-centrism and viewed Haitians are naturally inferior (Craton, 1995). In Brian Lee's documentary film Lakay, Dr. Eugene Newry, historian and former Bahamian Ambassador to Haiti, discusses this transfer of oppression and social stratification. The undocumented migration of Haitians to The Bahamas allowed Afro-Bahamians to look down upon another group of people. Haitians were being employed by people who would have ordinarily done the work on their own as well as performing those jobs. It is within this context that Bahamians began to refer to Haitians they employed as "my Haitian" which, according to Dr. Newry, is derogatory and used in the same sense that people would say my pet dog or cat. Quijano argues that through global capitalism, labor (paid and unpaid) became structurally linked with a particular race. Europeans received wages because they were human, and the exploited were associated with unpaid/nonwage labor because they were inferior. "The racial inferiority of the colonized implied that they were not worthy of wages. They were naturally obliged to work for the profit of their owners" (Quijano, 2000, p. 539). Furthermore, the control of a form of labor could also mean control over a particular group of people. The arrogance of saying my Haitian essentially means that Bahamians view themselves as superior, more human than Haitians. Haitians are their property.

What does this mark of racial difference look like? In a newspaper article discussing the threat Haitians posed to The Bahamas, a Bahamian stated "our identity is not Junkanoo, it's the way we live. We have always been a very passive society, but already we find ourselves accepting violence as a way of life" (Creole, 2005, p. 9). Haitians “... are perceived by Bahamians as less creolized than themselves, more African, unmodernized, superstitious, fatalistic, emotional and at least potentially violent" (Craton, 1995, p. 284). Additionally, "the Haitian Other is projected to the Bahamian Self as a natural inferior; primitive, backward, superstitious; naturally submissive but capable of mindless violence; not accustomed to democratic processes and therefore to be of necessity subjected; worthy of abuse" (Craton, p. 286).

A lot is being said within these statements. Quijano argues that racial classification placed Africans at the bottom of society which meant they were closer to nature (i.e. culturally inferior, less evolved, less human, uncivilized, and irrational). This also meant that in the degrees of humanity, Africans were the furthest away from Europeans who were completely human and thus naturally superior to all inferior groups. Because their bodies were closer to nature, Europeans believed that African bodies could be dominated, exploited, 
and were dispensable. All of the adjectives Bahamians use to describe Haitians articulates that they, Haitians, are considered non-human beings. They are closest to nature which is expressed through their primitiveness, irrationality, emotional behavior (which also has a gendered element), superstition, and the list can keep going. These descriptions also articulate that Bahamians view themselves as having benefited from modernity. They are democratic, modern, have Christian values, and are rational and scientific. They are more civilized (more creolized) and closer to human, if not completely human, than Haitians. These expressions of the coloniality of power are critical to understanding the treatment and representation of Haitians in The Bahamas.

Moreover, although Haitian-Bahamians can apply for citizenship, there is still an aura of stigmatization and the idea that they are not authentic Bahamians and thus do not deserve the benefits of society. This is evidenced by the distinctions between a "true true Bahamian" and a "paper Bahamian" which has created a socialized hierarchy in Bahamian citizenship. Naturalized citizens, whether they were born in The Bahamas or not, are not really Bahamians but (as the term implies) paper Bahamians. It should be made clear that this distinction is not a legal but social manifestation created in the Bahamian imagination (Caron, 2005, p. 4).

However, within this social hierarchy, it is apparent that Haitians cannot be Bahamian because they are not human. Although the terms true true Bahamian and paper Bahamian were created in the Bahamian imagination, they have tangible effects. In a letter to the editor of The Tribune, a Bahamian citizen, calling himself The Patriot, answers the question of citizenship:

Because a person is born in a garage, does not make that person a car. Because a person may happen to [be] born in a stable, does not make that person an animal....So being born in The Bahamas does not make one a Bahamian. A child born in The Bahamas of foreign parents must by international law take the nationality of his parents. Nationality and citizenship are not synonymous. (The Patriot, 2005, p. 4)

Although The Patriot does not speak for all Bahamians, statements and attitudes like these are prevalent in The Bahamas. To expound upon this point, for the International Organization of Migration report, researchers interviewed "...a senior government official who consistently referred to a 'Haitian'. On further questioning it was found that the 'Haitian' had a Bahamian passport which meant he was a Bahamian. However, in the mind of the official, this Bahamian citizen was still a 'Haitian'" (Johnson et al., 2005, p. 69). This attitude is not uncommon and is a reflection of Bahamians' unwillingness to accept and incorporate Haitians into their society. It is a reflection not only of everyday Bahamian attitudes but also ideas of the State. Bahamians have a distorted self-image which is a product of coloniality. Because of this, they view themselves as human, and thus Haitians, who are not humans, cannot be Bahamian.

In the land of their birth, in the only country that they know as home, many HaitianBahamians have reported feeling inferior, like a foreigner, and segregated. Yet, they speak with a Bahamian accent, dress like Bahamians, have Bahamian values, and share many of the same concerns as their peers. In an effort to assimilate into Bahamian society and not stand out from their Bahamian peers, some Haitian-Bahamians have attempted to hide their Haitian heritage. Some HaitianBahamians refuse to speak Creole in public because they do not want people to know they are of Haitian descent (Small, 2004). HaitianBahamians may anglicize their first name, 
surname, or both so that they do not stand out from their peers and thus are not recognizably Haitian. This too is an expression of coloniality because it is also a distorted sense of self. They believe these ideas about Haitians and in an effort to prove their humanity, show their peers and Bahamian society that they are just as human as them through their names, speech, and values.

These racialized images have played a significant role in promoting anti-Haitian sentiment, xenophobia, marginalization (legislative and cultural), and discrimination towards Haitians in The Bahamas. As a result, Bahamians have marginalized and socially constructed the images of the Haitian population through legislation passed during the era of independence, everyday constructions of Bahamian identity, and antiHaitian sentiment perpetuated by the media. All of these institutions maintain and reflect the coloniality of power. In effect, legislation and social constructions have sought to control the Haitian community and prevent them from being fully recognized or integrated into the mainstream of society. They control Haitian bodies through the exploitation of their labor as well as in the refusal to grant citizenship or regularize their stay which leaves them vulnerable to domination and exploitation.

\section{REFERENCES}

Alexander, J. M. (1994). Not just (any) body can be a citizen: The politics of law, sexuality and postcoloniality in Trinidad and Tobago and the Bahamas. Feminist Review, 48, 5-23. doi.org/10.1057/fr.1994.39

Bellegarde-Smith, P. (2004). Haiti: The breached citadel. Toronto: Canadian Scholars' Press.

Bethel, N. (2007). Roots or routes? Migrations of identity in The Bahamas. Yinna: Journal of The Bahamas Association for Cultural Studies, 2, 74-93. Available at http://www.nicobethel.net/nico-athome/academia/roots.html

Caron, E. D. (2005. February 16). Born Bahamians and 'paper' Bahamians [Editorial]. The Tribune, p. 4. Retrieved from http://dloc.com/UF00084249/00038/4j

Craton, M. (1995). The Bahamian self and the Haitian other: The migration of Haitians to and through The Bahamas, 1950-2000.
Immigrants and Minorities, 3, 265-288. doi.org/10.1080/02619288.1995.9974867

Craton, M., \& Saunders, G. (1998). Islanders in the stream: A history of the Bahamian people. Volume Two: From the ending of slavery to the twenty-first century. Athens: University of Georgia Press.

Creole will be the dominant language within ten years. (2005, November 10). The Tribune, p. 9. Retrieved from http://dloc.com/UF00084249/00251/9j

Fielding, W. J., Ballance, V., Scriven, C., McDonald, T., \& Johnson, P. (2008). The stigma of being "Haitian" in The Bahamas. The College of The Bahamas Research Journal, 14, 38-50. Retrieved from http://journals.sfu.ca/cob/index.php/files/arti cle/view/97

Haitians living in limbo. (2003, May 26). The Washington Times. http://www.washingtontimes.com/news/200 3/may/26/20030526-104012-

$5119 \mathrm{r} /$ ?page $=$ all 
Hall, S. (Ed.). (1997). Representation: Cultural representations and signifying practices. London, England: SAGE.

Herig, K. (2005, November 25). Bahamians of Haitian descent 'will make up swing vote in 10-15 years'. The Tribune, pp. 1, 10. Retrieved from http://ufdc.ufl.edu/UF00084249/00264

Johnson, P., Ballance, V., Fielding, W., MacDonald, T., Scriven, C., \& Stuart, D. (2006). Haitian migrants in The Bahamas 2005. Retrieved from http://www.iom.int/jahia/webdav/site/myahi asite/shared/mainsite/published_docs/books/ Haitian_Migrants_Report.pdf

Lee, B. (Writer and Producer). (2009). Lakay. The Bahamas: IMDbPro.

Maldonado-Torres, N. (2007). On the coloniality of being. Cultural Studies, 21(2), 240-270.

doi.org/10.1080/09502380601162548

Marshall, D. (1979). The Haitian problem: Illegal migration to The Bahamas. Kingston, Jamaica: Institute of Social and Economic Research, University of the West Indies.

McCollin, E. (2002). Resistance and the impact of Caribbean immigration on the development of Bahamian national identity. Journal of The Bahamas Historical Society, 21, 43-48.

Palmer, C. A. (1994). Tourism and colonialism: The experience of the Bahamas. Annals of Tourism Research, 21(4), 792-811. doi.org/10.1016/01607383(94)90084-1

Pierre, H. (2006). Haiti, rising flames from burning ashes: Haiti the phoenix. Lanham, ND: University Presses of America.

Quijano, A. (2000). Coloniality of power, eurocentrism, and Latin America. Nepentla: Views From the South, 1(3), 533-580. doi.org/10.1177/0268580900015002005
Richardson, B. C. (1983). Caribbean migrants: Environment and human survival on St. Kitts and Nevis. Knoxville: The University of Tennessee Press.

Robertson, J. (2001). The Haitian dilemma. In Etienne Dupuch Jr., Bahamas Handbook and Businessman's Annual (pp. 72-81). Nassau, Bahamas: Dupuch Publications.

Rommen, T. (1999). Home sweet home: Junkanoo as national discourse in the Bahamas. Black Music Research Journal, 19(1), 71-92. doi.org/10.2307/779275

Saunders, G. (2003). Bahamian society after emancipation. Kingston, Jamaica: Ian Randle.

Sears, A. (1994). The Haitian question in The Bahamas. Journal of The Bahamas Historical Society, 16, 10-20.

Small, M. (2004, August 26). Examining the impact of not belonging to any country. The Nassau Guardian. Retrieved from http://groups.yahoo.com/neo/groups/ethnobe at/conversations/topics/2189

Smith, A. D. (1991). National identity. London, England: Penguin.

The Patriot. (2005, April 5). Answering the question of who is a citizen. [Letter to the Editor] The Tribune, p. 4. Retrieved from http://dloc.com/UF00084249/00076/4j

Tinker, K. (2011). The migration of peoples from the Caribbean to The Bahamas. Gainesville: University Press of Florida.

Turnquest, P. G. (2005, February 26). I tell you one thing...I ain't learning Creole! The Tribune, p. 5. Retrieved from http://dloc.com/UF00084249/00047/5j

Yale Law School Lowenstein International Human Rights Clinic. (1994, June). Human Rights delegation report on Haitians in The Bahamas. Retrieved from http://avalon.law.yale.edu/diana/haitibahama asp 